\title{
Ductus arteriosus blood flow during first 48 hours of life
}

\author{
M R DRAYTON AND R SKIDMORE
}

Department of Paediatrics, Bristol Maternity Hospital, and Department of Medical Physics, Bristol General Hospital, Bristol

SUMmary A volumetric Doppler technique was used to measure net ductus arteriosus shunt during the first 48 hours of life in 30 infants of less than 33 weeks' gestation, and in 10 full term infants. In the full term infants a left to right shunt of $62 \mathrm{ml} / \mathrm{kg} / \mathrm{minute}(95 \%$ confidence limits 43-82) shortly after birth decreased rapidly over the first 12 hours and was not measurable by 48 hours. The preterm infants had smaller left to right shunts shortly after birth $-49 \mathrm{ml} / \mathrm{kg} / \mathrm{minute}$ (95\% confidence limits 38-59). There was no obvious subsequent change in the mean shunt, although by 48 hours there was greater variation in the size of the shunt. The respiratory distress syndrome did not affect the size of the ductal shunt, but the shorter the gestation period the larger the shunt by 48 hours. A ductal flow of greater than $70 \mathrm{ml} / \mathrm{kg} / \mathrm{minute}$ at 48 hours of age predicted the subsequent development of a ductal murmur with $75 \%$ sensitivity and $100 \%$ specificity.

During intrauterine life the ductus arteriosus shunts blood right to left, away from the high resistance pulmonary circulation into the descending aorta. After delivery vascular resistance and pressure fall rapidly in the pulmonary circulation and rise in the systemic circulation. The reversal of the pressure gradient across the ductus arteriosus leads to a net left to right shunt until functional closure of the ductus occurs. In preterm infants closure of the ductus is often delayed, leading to persisting left to right or bidirectional shunts that may decrease lung compliance, increase the work load of the left ventricle, and decrease perfusion of the myocardium and other systemic vascular beds. ${ }^{1}$ During the early days of life these ductal shunts are not usually accompanied by the cardiac murmur which is characteristic of them after the first week. ${ }^{23}$

The time of closure of the ductus arteriosus has been studied at necropsy, ${ }^{4}$ and by various catheterisation $^{1}{ }^{\text {5-6 }}$ and echocardiographic ${ }^{7}$ techniques. These techniques are either invasive and difficult to interpret, ${ }^{8}$ or are sensitive to small and functionally irrelevant jets of blood flowing through the ductus arteriosus. This study quantitatively compared the time course of ductal shunting in both full term and preterm infants during the first 48 hours of life.

\section{Patients and methods}

The velocity of blood flowing within the aorta may be calculated from the frequency shift of ultrasound scattered back from moving blood corpuscles according to the formula:

$$
\text { velocity }=\text { frequency shift } \times \mathrm{c} / 2 \mathrm{f} \cos \mathrm{A}
$$

where $c=$ speed of ultrasound in tissue $(1500$ $\mathrm{cm} /$ second); $\mathrm{f}=$ frequency of ultrasound, and $\mathrm{A}=$ Doppler angle.

If the aorta is evenly covered by the ultrasound beam then the average time and spatial velocity may be derived from the frequency power spectrum of the shifted Doppler signal. By using the full power spectrum, the average velocity may be accurately calculated, irrespective of variation in the velocity profile across the vessel lumen. Volume flow is the product of average velocity and aortic cross sectional area. If flow is measured in this way just above and just below the origin of the ductus arteriosus then net ductal flow may be calculated by subtraction.

In this study a duplex ultrasound scanner (ATL Mk 600) was used to identify the aorta and locate the pulsed Doppler sample volume and measure the Doppler angle using the real time image. The 
scanner was interfaced to a microcomputer (Apple IIe), and the full Doppler power spectrum from about five cardiac cycles was fed into the memory bifore being processed to remove noise and the calculation of the average velocity was made; it was then stored on disc. A $5 \mathrm{~mm}$ pulse gate and $100 \mathrm{~Hz}$ wall filter were used. Imaging was performed at 7.5 $\mathrm{MHz}$ and Doppler studies at $5 \mathrm{MHz}$. The Doppler sample volume was placed in the proximal ascending aorta from a substernal four chamber view, in the preductal aorta from a suprasternal or left supraclavicular long axis view, and in the postductal aorta close to the diaphragm from a low substernal long axis view. The combination of a discrete pulsed Doppler sample volume and duplex Doppler imaging allowed us to confirm the precise origin of the Doppler signals.

The aortic diameter at the three sites of Doppler velocity sampling was measured using precordial $\mathbf{M}$ mode imaging from which the area could be calculated by assuming a circular cross section. Perpendicular preductal aortic $\mathbf{M}$ mode measurements were sometimes impossible; measurements were then made from the real time image. These usually correlated closely with the $\mathrm{M}$ mode measurements made postductally.

Volume flow Doppler systems are susceptible to both systematic and random errors. Systematic errors are usually due to the preferential sampling of central stream velocities. These were minimised in this study by calibrating the system in the laboratory using a range of vessel diameters in a pulsatile flow rig that was filled with human blood. Errors in the measurement of vessel diameter and Doppler angle are usually random and their effect was diminished by taking the mean of at least four recordings from each site.

The Wilcoxon signed rank matched pairs, MannWhitney U (2 tailed) or Fisher's exact tests were used as appropriate to calculate the significance of differences.

The group born at term comprised 10 infants of greater than 37 weeks' gestation who had no perinatal problems (range 38-41 weeks, median 40 weeks; birth weight 2730-3960 g, median $3275 \mathrm{~g}$ ). Those infants who were bottle fed received 60 and $90 \mathrm{ml} / \mathrm{kg} /$ day on the first and second days of life, respectively.

The preterm group comprised 30 infants born at the Bristol Maternity Hospital between June 1985 and January 1986 at 33 completed weeks of gestation or less. Those with congenital malformation (range 24-32 weeks, median 30 weeks, birth weight 760-2140 g, median $1430 \mathrm{~g}$ ) were excluded. Table 1 summarises their clinical characteristics. A standard fluid regimen of $60-80$ and $90-120 \mathrm{ml} / \mathrm{kg} /$ day was given on the first and second days of life, respectively.

To assess the effect of respiratory distress the mean of the alveolar to arterial oxygen gradients at the time of each study was calculated. A division point of $200 \mathrm{~mm} \mathrm{Hg}$ was arbitrarily chosen to separate the infants with moderate or severe respiratory disease from those with mild or absent disease. To eliminate bias due to gestational age we matched 13 infants from each group to within one week.

Doppler recordings were made initially between 1 and 2 hours of age, and then at 6 hours (in the preterm group only), 12 hours, 24 hours, and 48 hours of age. Parental consent was obtained before Doppler examination of both term and preterm infants.

\section{Results}

In the term infants the mean ductal shunt at 1-2 hours of age was $62 \mathrm{ml} / \mathrm{kg} /$ minute left to right $(95 \%$ confidence limits 43 to 82 ). Over the first 12 hours of life the shunt had reduced to $14 \mathrm{ml} / \mathrm{kg} /$ minute $(95 \%$ confidence limits -6 to $+33, p=0.005$ ), and by 48 hours to $0.5 \mathrm{ml} / \mathrm{kg} /$ minute ( $95 \%$ confidence limits -10 to $+11, p=0.005$ ) (figure).

In the preterm infants the mean ductal shunt at 1-2 hours was $49 \mathrm{ml} / \mathrm{kg} /$ minute left to right $(95 \%$ confidence limits 38 to 59 , significantly less than the shunt in the term group, $p=0.04$ ). Over the following 48 hours there was no significant change in the size of the mean ductal shunt. There was, however, a progressive fall in the median size of

Table 1 Clinical characteristics of 30 preterm infants studied

\begin{tabular}{ll}
\hline Clinical feature & No of cases \\
\hline Sex (M:F) & $13: 17$ \\
Reason for delivery: & \\
Spontaneous preterm labour & 18 \\
Antepartum haemorrhage & 5 \\
Prolonged rupture of membranes & 6 \\
$\quad$ Hypertension & 1 \\
Delivery (vaginal:caesarian section) & $18: 12$ \\
Maternal drugs during labour or delivery: & \\
General anaesthesia & 10 \\
Epidural anaesthesia & 7 \\
Opiate analgesia & 3 \\
$\quad$ Oxytocin & 3 \\
Singletons:twins & $22: 8$ \\
Respiratory distress syndrome & 16 \\
Respiratory support during first 48 hours: & \\
Positive pressure ventilation & 22 \\
Continuous positive airways pressure & 5 \\
Received muscle paralysis & 3 \\
Survived to hospital discharge & 29 \\
\hline
\end{tabular}



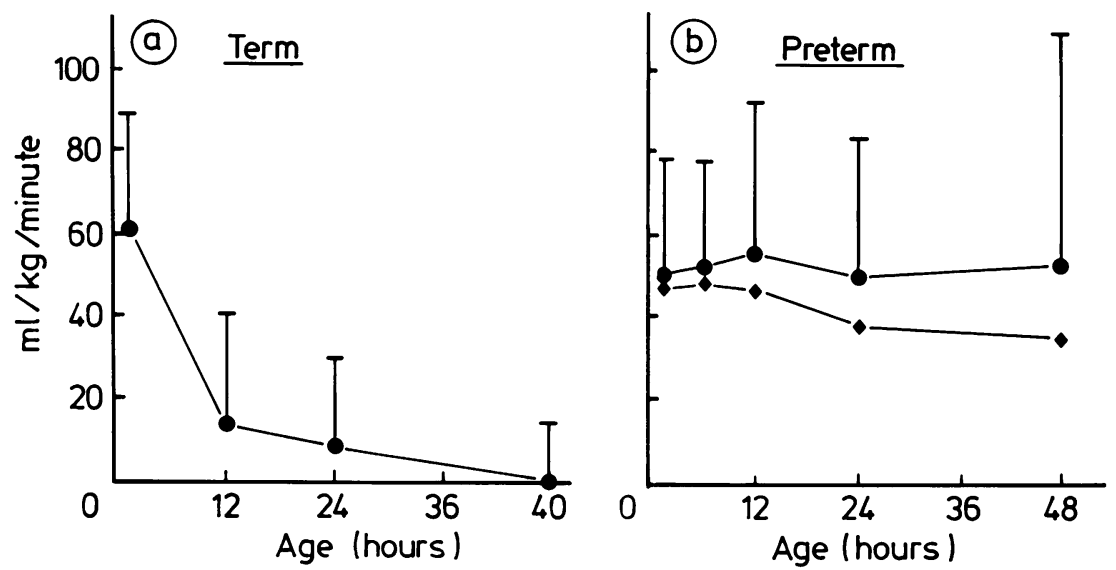

Figure Net ductal flow $(\mathrm{ml} / \mathrm{kg} /$ minute) in term $(n=10)$ and preterm $(n=30)$ infants during first 48 hours of life. Flow left to right expressed as positive. Points represent mean $(S D)(O)$ or median $(\diamond)$.

ductal shunt and a progressive widening of the variety of sizes of shunts (figure). The ductal shunts in the preterm infants were significantly greater than in the term infants from 12 hours of age $(p=$ 0.0008).

There was no significant difference in size of ductal shunt at any age between the matched groups with severe and mild or absent respiratory distress (table 2).

Shortly after birth there seemed to be no difference dependent on gestational age in the size of ductal shunt. Although there were only four infants of less than 27 weeks' gestation surviving at 48 hours of age, three of them had ductal shunts greater than $70 \mathrm{ml} / \mathrm{kg} /$ minute (one as large as $212 \mathrm{ml} / \mathrm{kg} /$ minute) Of the remaining 24 infants studied of gestational age from 27 to 33 weeks (one infant was too unstable to study at 48 hours), only three had ductal shunts greater than $70 \mathrm{ml} / \mathrm{kg} /$ minute at 48 hours (correlation coefficient between shunt at 48 hours and gestational age, $r=-0.47, p=0.01)$.

During the study no cardiac murmurs were heard, but nine infants subsequently developed characteristic ductal murmurs. Of the 28 infants studied at 48

Table 2 Median ductal shunts in respiratory distress syndrome (ml/kg/minute)

\begin{tabular}{|c|c|c|c|c|c|c|}
\hline \multirow{2}{*}{$\begin{array}{l}\text { Extent of } \\
\text { respiratory } \\
\text { distress syndrome }\end{array}$} & \multicolumn{6}{|c|}{ Age (hours) } \\
\hline & 1.5 & 6 & 12 & 24 & 48 & $\begin{array}{l}\text { Mean } \\
(0-48)\end{array}$ \\
\hline Minimal & 50 & 47 & 30 & 51 & 32 & 43 \\
\hline Severe & 43 & 55 & 50 & 35 & 37 & 38 \\
\hline
\end{tabular}

hours of age, all of the six with ductal shunts of greater than $70 \mathrm{ml} / \mathrm{kg} /$ minute went on to develop murmurs, while only two with smaller shunts at 48 hours later developed murmurs (sensitivity $75 \%$, specificity $100 \%$; Fisher's exact test $\mathrm{p}=0.0001$ ).

\section{Discussion}

Doppler ultrasound offers a safe and non-invasive technique for the assessment of the circulation in newborn infants. It has been used to investigate the cerebral circulation, ${ }^{9}$ for the measurement of cardiac output, ${ }^{10}$ and in the diagnosis of congenital heart disease. ${ }^{11}$ This study extends the latter application by measuring flow in the aorta above and below the level of the ductus arteriosus, thus allowing calculation of the net flow through the duct by subtraction. A similar technique has been used to assess bloodflow to the head and neck. ${ }^{12}$ Direct Doppler measurement of flow within the ductus is not feasible as angle and diameter are rarely measurable from the real time image.

The major limitation of volume-flow Doppler techniques is its lack of accuracy ${ }^{13}$; this assumes even greater importance when two measured flows are subtracted as in this study. Systematic error was minimised by laboratory calibration of the system using a pulsatile flow rig in which blood flow could be precisely, accurately, and independently measured. Random error in volumetric Doppler methods derives mainly from inaccuracy of the measurement of the Doppler angle and the vessel diameter.$^{13}$ Error from both sources was minimised by making multiple measurements at each site and by comparing flow sequentially in groups of infants. 
This new technique provides physiological information which cannot otherwise be obtained without unjustifiably invasive techniques. It may also provide useful clinical information about the size of large ductal shunts in individual patients, but with current machines it is time consuming, requires great care, and is progressively less accurate the smaller the ductal shunt. Doppler techniques that use an analysis of wave form shape may be more useful for routine clinical assessment of the size of ductal shunts. ${ }^{14} 15$

The technique used in this study measures the net ductal shunt integrated over several seconds. The measurement of a net left to right shunt in an infant does not preclude there being a right to left component at some point in the cardiac cycle. At the time of the first study (between 1 and 2 hours of age) in both term and preterm infants the net ductal shunt was left to right, even in the presence of the respiratory distress syndrome. This confirms previous reports that the major right to left cardiac shunt in preterm infants with the respiratory distress syndrome is at atrial rather than ductal level. ${ }^{16}$ Placing the Doppler sample volume within the ductus itself shows that initially the flow is bidirectional-right to left in early systole, becoming left to right in late systole and diastoleconfirming previous studies using catheters. ${ }^{17}$

The size of the ductal shunt is determined by the pressure gradient between the systemic and pulmonary circulations, the degree of ductal constriction, and possibly by the angle at which the ductus joins the aorta. The net left to right shunt indicates that the mean pulmonary artery pressure is below the systemic pressure even in respiratory distress syndrome. The relatively smaller shunt shortly after birth in the preterm group, compared with that of the term group, probably represents a decreased aortopulmonary gradient due to delayed fall in pulmonary artery pressure.

As far as we know this is the first report of a noninvasive volumetric technique to measure the rate of closure of the ductus arteriosus. The rapid diminution in ductal shunt in the term infants must reflect the rapid closure of the ductus itself. The time to closure is shorter than has been suggested in other studies, which have looked qualitatively at the effect of the ductal shunt on the pulmonary artery waveform. ${ }^{7}$ These studies may have been measuring small and functionally irrelevant ductal jets that cause disproportionately large disturbances within the pulmonary artery. In the preterm group no change in mean ductal flow over the first 48 hours, a progressive decrease in median flow, and an increase in variance within the group indicate that in most infants there was some decrease in shunting, but that this was balanced by a few infants in whom the size of the shunt progressively increased. Although the numbers were small, it seemed that the infants with increasing shunts were usually younger than those in whom they decreased. Interestingly, in this study, contrary to some previous reports, ${ }^{18}$ we found that the respiratory distress syndrome did not influence the size of shunt or rate or ductal closure. The previous studies, however, did not attempt to separate the independent influences of prematurity and respiratory distress syndrome. Either the latter has no effect on ductal tone, or the effects of persisting ductal patency are counteracted by increased pulmonary vascular tone.

This study confirms previous reports of pronounced ductal shunts without characteristic ductal murmurs, particularly within the first few days of life. ${ }^{23}$ Clinical reference to 'opening of the duct' in preterm infants may be inaccurate: in most cases the duct will have been patent from birth and any increase in ductal shunt may be due to an increasing gradient between systemic and pulmonary pressures. The absolute values for ductal shunts measured in this study, however, even in the preterm group, are considerably smaller than those recorded in infants with ductal murmurs, wide pulse pressure, and incipient cardiac failure in the second and third weeks of life. The silence of early ductal shunts may be due to a combination of their small aortopulmonary gradients, their large calibre, and their small volume, which all contribute to a lack of turbulence.

We do not know how much clinical importance to attach to these early and usually small left to right ductal shunts. We speculate that during the early hours of life the sick or preterm infant may not be able to tolerate even an average shunt of $25 \%$ of left ventricular output because of the stressed and perhaps asphyxiated myocardium. If left ventricular output is not increased by an amount equalled by that of the ductal shunt then peripheral perfusion will be affected, especially that of the gastrointestinal tract, kidneys, and possibly that of the brain. At the same time the ductal shunt may exacerbate lack of compliance of lungs which are already atelectatic. Further study is required.

Interestingly, the size of ductal shunt measured at 48 hours was predictive of subsequent ductal murmurs. This suggests that many infants develop persistent ductal patency even at that early age. If this is so, Doppler ultrasound scanning might be used to select those infants who could benefit from pharmacological or other intervention to promote ductal closure. Again further study is required.

We thank Drs P M Dunn, P J Fleming, and B D Speidel for permission to study patients under their care. 


\section{References}

${ }^{1}$ Ruddolph AM, Drorbaugh JE, Auld PAM, Rudolph AJ, Nadas AS, Smith CA, Hubbell JP. Studies on the circulation in the neonatal period. The circulation in the respiratory distress syndrome. Pediatrics 1961;27:551-66.

2 Thibeault DW, Emmanouilides GC, Nelson RJ, Lachman RS, Rosengant RM, Oh W. Patent ductus arteriosus complicating the respiratory distress syndrome in preterm infants. $J$ Pediatr 1975;86:120-6.

${ }^{3}$ McGrath RL, McGuiness GA, Way GL, Wolfe RR, Nora JJ, Simmons MA. The silent ductus arteriosus. J Pediatr 1978;93:110-3.

${ }^{4}$ Wilson RR. Post-mortem observations on contraction of the human ductus arteriosus. $\mathrm{Br}$ Med $J$ 1958;i:810-1.

5 Prec KL, Cassels DE. Dye dilution curves and cardiac output in newborn infants. Circulation 1955;11:789-98.

${ }^{6}$ Moss AJ, Emmanouilides G, Duffie ER Jr. Closure of the ductus arteriosus in the newborn infant. Pediatrics 1963;32: 25-30.

7 Gentile R, Stevenson G, Dodey T, Franklin D, Kawabori I, Pearlman A. Pulsed Doppler echocardiographic determination of time of ductal closure in normal newborn infants. $J$ Pediatr 1981;98:443-8.

${ }^{8}$ Rowe RD. Patent ductus arteriosus. In: Keith JD, Rowe RD, Vlad P, eds. Heart disease in infancy and childhood 3rd ed. New York: Macmillan, 1978:420-1.

9 Drayton MR, Skidmore R. Doppler ultrasound in the neonate. Ultrasound Med Biol 1986;12:761-72.

10 Alverson DC, Eldridge MW, Dillon T, Yabek SM, Berman W.
Noninvasive pulsed Doppler determination of cardiac output in neonates and children. J Pediatr 1982;101:46-50.

"Hatle L. Angelsen B, eds. Doppler ultrasound in cardiology. Philadelphia: Lee and Febiger, 1985.

12 Drayton MR, Skidmore R. Vasoactivity of the major intracranial arteries in newborn infants. Arch Dis Child 1987;6:236-40.

13 Gill RW. Measurement of blood flow by ultrasound: accuracy and sources of error. Ultrasound Med Biol 1985;11:625-41.

${ }^{14}$ Serwer GA, Armstrong BE, Anderson PAW. Noninvasive detection of retrograde descending aortic flow in infants using continuous wave Doppler ultrasonography. $J$ Pediatr 1980;97:394-400.

15 Serwer GA, Armstrong BE, Anderson PAW. Continuous wave Doppler ultrasonographic quantitation of patent ductus arteriosus flow. J Pediatr 1982;100:297-9.

16 Roberton NRC, Dahlenburg GW. Ductus arteriosus shunts in the respiratory distress syndrome. Pediatr Res 1969;3:149-59.

${ }^{17}$ Spach MS, Serwer GA, Anderson PAW, Canent RV, Levin AR. Pulsatile aortopulmonary pressure-flow dynamics of patent ductus arteriosus in patients with varying hemodynamic states. Circulation 1980;61:110-22.

18 Kitterman JA, Edmunds LH, Gregory GA, Heyman MA, Tooley WH, Rudolph AM. Patent ductus arteriosus in premature infants. Incidence, relation to pulmonary disease and management. N Engl J Med 1972;287:473-77.

Correspondence to $\operatorname{Dr} \mathrm{M}$ Drayton, Bristol Maternity Hospital, Bristol BS2 8EG.

Received 26 May 1987 